\title{
Application Model of Pranic Healing Therapy for Emotional Stress Using Accurate Bio-Well GDV Camera
}

\author{
Cahyaning Puji Astuti* , Melyana Nurul Widyawati ${ }^{1}$, and Suryono Suryono ${ }^{2}$ \\ ${ }^{1}$ Master of Applied Science in Midwifery, Poltekkes Kemenkes Semarang - Indonesia \\ ${ }^{2}$ Physics Department, Faculty of Mathematics and Natural Sciences, Diponegoro University, Semarang - Indonesia
}

\begin{abstract}
Pregnancy is a period of both hormonal and non-hormonal overall change in the body. Emotional instability is commonly experienced by women during this period. However, this somewhat complex issue is often not addressed optimally. Pharmacological therapies using $C P Z$ and lithium are often administered, but they have effects for the body. Therefore, there is a need to administer non-pharmacological therapy that has minimum side effects. This research aims to increase the healthy energy within the body using Pranic Healing, which is measured by the Bio-Well GDV camera. This research employed the pretest-posttest method on two groups (treatment and control) using the Randomized Controlled Trial design. Pranic Healing therapy was performed for 30 minutes once a week for 3 weeks, while GDV measurement was performed once a week for 4 weeks. Paired t-test results for Pranic Healing on emotional pressure showed p-value of $0.0001(<0.05)$ for posttest2 and p-value of $0.005(<0.05)$ for posttest3. Meanwhile, the control group did not indicate any changes in emotional stress both before and after treatment. It is found that Pranic Healing as measured using a bio-well GDV camera is capable of improving health energy within the body by relieving emotional stress experienced in trimester III primigravida.
\end{abstract}

Keywords: Maternal health; Pranic Healing; Bio-well GDV Camera; Emotional stress.

\section{Introduction}

The health condition in primigravida includes the tendency to be unstable under emotional stress. Emotional stress is affected by both hormonal and nonhormonal factors. Currently available pharmacological treatment using CPZ, Lithium and other antipsychotic agents come with side effects for the body. (Management of common adverse effects of antipsychotic medications) (Long-term neurodevelopmental consequences of intrauterine exposure to lithium and antipsychotics: a systematic review and meta-analysis) $[1,2]$.

This research focuses on the healing method using the energy field to diagnose and cure certain ailments. In quantum physics, this phenomenon is based on individual awareness in taking a role in the quantum nature to actualize oneself and explaining the psychoneuroimmunology study explained that the body, mind, and soul are interconnected. When one's mind is focused on something, the will be ways that affect the way the bodywork as to allow the mind to feel something. These facts show that the body and the mind are not two separate entities but an entirely integrated system instead [3].

What happens with the bodily mechanism is that the brain affects the immune system via hypothalamus and pituitary, the neuroendocrine system, the autonomic nervous system, and the release of cytokinin. That process directly influences the activities of the immune system performed by immune peptides such as interleukin, corticotrophin, and endorphin. This biological fact further emphasizes that the mind, feeling, emotion, and perception do play roles in altering the immune system [4].

The use of a GDV camera to measure and analyze results of pranic healing administration reveals an individual's aura or energy field that surrounds an individual's body and records any changing taking place during therapy. GDV camera allows the study of brain wave patterns of healing energy that are in tune with the pattern of earth magnetic resonance, at 7.8 to $8 \mathrm{~Hz}$. Based on that explanation, all materials contain energy and the human body is a dynamic entity that can interact well with that energy for healing purposes. This healing energy is directly proportional to controlled emotional stress with the help of pranic healing $[5,6]$.

\section{Method}

This research employed the Randomized Controlled Trial (RCT) design, which means that it is truly experimental research. The research was carried out at Ngesti Widodo Clinic in Ungaran in Indonesia. Respondents were divided into two groups of intervention and control. The intervention group

\footnotetext{
* Corresponding author: astuticahyaning@gmail.com
} 
consists of trimester III primigravida who has to undergo pranic healing, whereas the control groups consist of trimester III primigravida who was given typical care and treatment.

The population of respondents was 164 pregnant women. Out of those, 114 belong to the exclusion criteria. Other than that, 8 respondents had to be dropped out. This means that 42 subjects met the inclusion criteria of this research, and were divided into intervention and control groups. They then underwent intervention using pranic healing and standard midwifery care, respectively.

This research has successfully used a GDV camera during pranic healing that focuses on the health energy of trimester III primigravida. Pranic healing therapy was performed for 30 minutes once a week for 3 weeks, while GDV measurement was performed once a week for 4 weeks. The analysis was conducted by comparing the results of pretest and posttests 1,2 , and 3 . The time series analysis method was employed as there were 4 repeated measurements for both the intervention and the control group.

\section{Result and Discussion}

Univariate analysis for characteristics of research subjects including age, occupation, and pregnancy period has been performed. The results of that analysis reveal descriptions of frequency, mean, and standard deviation.

Bivariate analysis for normality test using ShapiroWilk calculation has also been performed. The dependent bivariate analysis then proceeded for normal data distribution using parametric testing (paired t-test), whereas abnormal data distribution made use of nonparametric testing (Wilcoxon test). On the other hand, independent bivariate analysis proceeded for normal data distribution using parametric testing (unpaired ttest), while abnormal data distribution employed nonparametric testing (Mann-Whitney test).

The following image depicts the GDV camera result showing unhealthful condition on milk glands, liver, kidneys, sacrum organs, jaws, respiratory system, and spleen. The result of GDV camera measurement from one respondent in the control group during the pretest is shown in Figure 1. Meanwhile, the result of GDV camera measurement from one respondent in the intervention group during the pretest is shown in Figure 2.

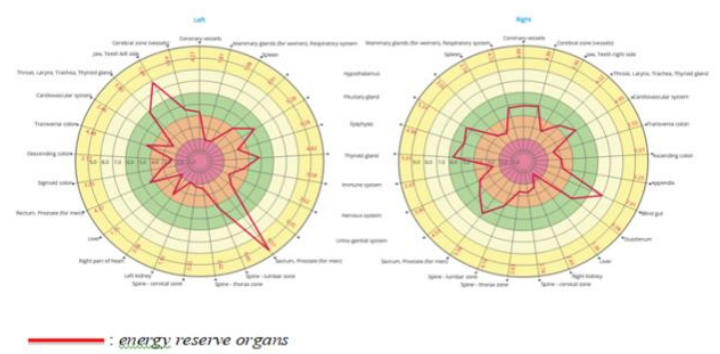

Fig. 1. Physical condition pretest result from a respondent in the control group.

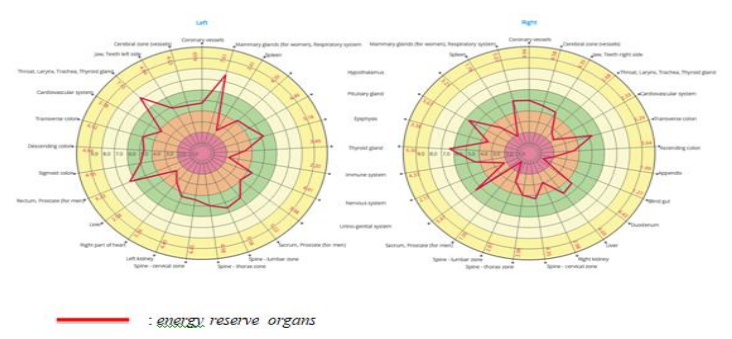

Fig. 2. Physical condition pretest result from a respondent in the intervention group.

Measurement analysis for emotional stress was performed during pretest and posttest for the intervention group with pranic healing and the control group without pranic healing. This measurement involves the evaluation of emotional stress. Categories for emotional stress are calm (0-2), optimal (2-3), anxious (3-4), stressed (4-6), elevated stress (6-8), very stressed (8-10). Table 1 shows a measure of emotional stress.

Table 1. Frequency of emotional stress during pretest and posttest for the intervention group with Pranic Healing and for the control group without Pranic Healing.

\begin{tabular}{|c|c|c|c|c|c|c|c|c|c|}
\hline \multirow[t]{2}{*}{ Group } & \multirow{2}{*}{$\begin{array}{c}\text { Emotional } \\
\text { Pressure } \\
\text { Classification }\end{array}$} & \multicolumn{2}{|c|}{ Pretest } & \multicolumn{2}{|c|}{ Post test 1} & \multicolumn{2}{|c|}{ Post test2 } & \multicolumn{2}{|c|}{ Post test3 } \\
\hline & & $\mathrm{F}$ & $\%$ & $\mathrm{~F}$ & $\%$ & $\mathrm{~F}$ & $\%$ & $\mathrm{~F}$ & $\%$ \\
\hline \multirow{7}{*}{ Control } & Calm & 2 & 14,3 & 3 & 21,4 & 3 & 21,4 & 1 & 7,1 \\
\hline & Optimal & 9 & 64,3 & 7 & 50 & 8 & 57,2 & 10 & 71,5 \\
\hline & Anxiety & 1 & 7,1 & 4 & 28,6 & 2 & 14,3 & 2 & 14,3 \\
\hline & Stres & 2 & 14,3 & - & - & 1 & 7,1 & 1 & 7,1 \\
\hline & Heightened & - & - & - & - & - & - & - & - \\
\hline & High & - & - & - & - & - & - & - & - \\
\hline & Total & 14 & 100 & 14 & 100 & 14 & 100 & 14 & 100 \\
\hline \multirow{7}{*}{$\begin{array}{c}\text { Pranic } \\
\text { Healing }\end{array}$} & Calm & - & - & - & - & 2 & 14,3 & 1 & 7,1 \\
\hline & Optimal & 9 & 64,3 & 12 & 85,8 & 11 & 78,6 & 13 & 92,9 \\
\hline & Anxiety & 4 & 28,6 & 1 & 7,1 & 1 & 7,1 & - & - \\
\hline & Stres & 1 & 7,1 & 1 & 7,1 & - & - & - & - \\
\hline & Heightened & - & - & - & - & - & - & - & - \\
\hline & High & - & - & - & - & - & - & - & - \\
\hline & Total & 14 & 100 & 14 & 100 & 14 & 100 & 14 & 100 \\
\hline
\end{tabular}

Table 1 reveals that during pretest respondents in the control group are made up of the followings; 9 respondents $(64.3 \%)$ are in optimal condition, 2 respondents $(14.3 \%)$ are calm, 1 respondent $(7.1 \%)$ is anxious, and 2 respondents (14.3\%) are stressed. Meanwhile, respondents in the intervention group (with pranic healing) are made up of the following; 9 respondents $(64.3 \%)$ are in optimal condition, 4 respondents $(28.6 \%)$ are anxious, and 1 respondent $(7.1 \%)$ is stressed.

On the other hand, results from posttest 1 show that for the control group; the number of respondents experiencing anxiety increases to 4 (from 1 person), whereas for the intervention group; the number of experiencing optimal condition increases from 9 to 12 persons, and there is a decrease in the number of respondents experiencing anxiety, from 4 to 1 person.

Results from posttest 2 show that in the control group; there are 3 calm respondents (the same as from posttest 1), there are 8 respondents in optimal condition, 2 respondents experiencing anxiety, and 1 respondent is stressed. In the meantime, in the intervention group; 
there has been an increase in the number of respondents experiencing a better emotional state, with 2 calm respondents, 11 respondents in optimal condition, and only 1 respondent still anxious.

Results from posttest 3 show that for the intervention group; 1 respondent $(7.1 \%)$ is calm, and 13 respondents $(92.9 \%)$ are in optimal condition. This means that respondents are in the better emotional state compared to their conditions during pretest, posttest 1 and posttest 2. Meanwhile, for the control group; 1 respondent $(7.1 \%)$ is calm, 10 respondents $(71.4 \%)$ are in optimal condition, 2 respondents $(14.3 \%)$ are anxious, and 1 respondent $(7.1 \%)$ is stressed. This means that the number of respondents experiencing anxiety and stress are the same as the one during posttest 2.

Results of measurement analysis for mean, standard deviation, and mean rank values from respondents during the pretest, posttest 1 , posttest 2 , and posttest 3 , in terms of emotional stress are shown in Table 2.

Table 2. Measured mean, standard deviation, and mean rank values from respondents during pretest, posttest 1, posttest 2 , and posttest 3 , in terms of emotional stress.

\begin{tabular}{|c|c|c|c|c|c|}
\hline Group & Test & Mean & Std Dev & $\begin{array}{l}\text { Mean } \\
\text { Rank }\end{array}$ & Pvalue* \\
\hline \multirow{4}{*}{ Control } & Pre Test & 2,6943 & 0,7824 & 2,82 & \multirow{4}{*}{0,164} \\
\hline & Post test 1 & 2,4850 & 0,5440 & 2,43 & \\
\hline & Post test 2 & 2,6007 & 1,007 & 1,89 & \\
\hline & Post test 3 & 2,7114 & 0,8221 & 2,86 & \\
\hline \multirow{4}{*}{$\begin{array}{l}\text { Pranic } \\
\text { Healing }\end{array}$} & Pre Test & 2,9021 & 0,5739 & 3,54 & \multirow{4}{*}{0,001} \\
\hline & Post test 1 & 2,6350 & 0,5682 & 2,82 & \\
\hline & Post test 2 & 2,2586 & 0,3005 & 1,79 & \\
\hline & Post test 3 & 2,3286 & 0,2512 & 1,86 & \\
\hline
\end{tabular}

Table 2 reveals that mean values for the control group are 2.6943 for pretest, 2.485 for posttest $1,2.6007$ for posttest 2, and 2.7114 for posttest 3 , with p-value of $0.164>p=0.05$. As the mean values from pretest to posttest 3 are almost the same, it can be concluded that there is no significant difference in the emotional state from pretest to posttest 3. On the other hand, mean values for the intervention group are 0.9021 for pretest, 2.635 for posttest $1,2.2586$ for posttest 2 , and 2.3286 for posttest 3 , with a p-value of $0.001<0.05$. Therefore, it can be concluded that there is a significant difference in the emotional state from pretest to posttest 3.

Results of difference test analysis for each value from pretest to posttest 3 for both the control and the intervention groups are given in Table 3.

Table 3. Measurement analysis for mean, standard deviation, and mean rank values from respondents during pretest, posttest 1 , posttest 2 , and posttest 3 , in terms of emotional stress.

\begin{tabular}{|c|c|c|}
\hline \multirow{2}{*}{ Group } & Test & P-value \\
\hline \multirow{3}{*}{ Control } & Pretest - Posttest 1 & $0.198^{*}$ \\
\cline { 2 - 3 } & Pretest - Posttest 2 & $0.1^{*}$ \\
\cline { 2 - 3 } & Pretest - Posttest 3 & $0.95^{*}$ \\
\hline \multirow{3}{*}{ Intervention } & Pretest - Posttest 1 & $0.102^{* *}$ \\
\cline { 2 - 3 } & Pretest - Posttest 2 & $0.001^{* *}$ \\
\cline { 2 - 3 } & Pretest - Posttest 3 & $0.005^{* *}$ \\
\hline \multirow{2}{*}{ Note: * Wilcoxon Test ** Paired T-Test }
\end{tabular}

Results of Wilcoxon Sign Rank test in Table 3 show that there is no significant difference in the emotional state among respondents, with a p-value of pretest to posttest 1 at $0.198>\mathrm{p} 0.05$, pretest to posttest 2 at $0.1>$ p 0.05 , and pretest to posttest 3 at $0.95>$ p 0.05 . Results of Wilcoxon Sign Rank test in Table 4 show that there is significant difference in emotional state among respondents, with $\mathrm{p}$-value of pretest to posttest 2 at $0.001>$ p 0.05 , pretest to posttest 3 at $0.005>$ p 0.05 , while pretest to posttest 3 show no significant difference in emotional state among respondents with $\mathrm{p}$-value at $0.102>$ p 0.05 .

Differences in an emotional state between the control group and the intervention group prior and after pranic healing therapy are shown in Table 4.

Table 4. Differences in emotional state between the control group and the intervention group before and after pranic healing therapy.

\begin{tabular}{|c|c|c|}
\hline Variable & Test & P value* \\
\hline \multirow{4}{*}{ Emotional Stress } & Pretest & 0.161 \\
\cline { 2 - 3 } & Posttest 1 & 0.37 \\
\cline { 2 - 3 } & Posttest 2 & 0.55 \\
\cline { 2 - 3 } & Posttest 3 & 0.223 \\
\hline
\end{tabular}

Differences in emotional state variables between the control group and the intervention group before and after pranic healing therapy are shown in Table 4 . The $p$ values for emotional stress variable from MannWhitney test between the control and the intervention group are; $p=0.161>0.05$ for pretest, $p=0.37>0.05$ for posttest $1, \mathrm{p}=0.55>0.05$ for posttest 2 , and $\mathrm{p}=0.223$ $>0.05$ for posttest 3 . Therefore, there is a difference in the variable of emotional stress between the control group and the intervention group before and after therapy.

\section{Discussion}

Based on those results, administration of pranic healing significantly affects health condition by stabilizing the emotional state. This is in line with the health and disease paradigm which states that the administration of pranic healing is one of the therapies that focuses on bodily health via energy. This paradigm emphasizes the fact that emotional health is closely related to the wellbeing of the physical mechanism [7].

Earlier researches have shown that spiritual healing using a higher state of energy has proven to reduce depression and is greatly beneficial to improving health [8].

The mechanism that facilitates the administration of pranic healing for health condition by stabilizing emotional condition is by channeling energy (chi) via the chakra of the human body. Chakras are acupuncture points that also serve as outlets for human body energy. The chakras activated by pranic healing reach prime condition and help to absorb and distribute energy all 
over the body and hence, improve bodily functions that used to lack energy [9].

Effectiveness of pranic healing in improving health condition using energy to stabilize emotional state has been proven to provide significant results, in comparison to the use of pharmaceuticals [2]. This is in line with the results of earlier researches showing comparative improvement as evidenced by the GDV camera. This kind of researches are represented in the book entitled Human Energy Field: Study with GDV bioelectrography, which further proves that bioelectrographic treatment can be used as an alternative method to provide preventive healthcare (electrophotonic analysis) [10-12].

\section{Conclusion}

There has been physical health improvement as proven by detected emotional with the help of Bio-well GDV Camera after intervention with pranic healing for trimester III primigravida.

\section{References}

1. E.B. Robins, J. Merryman, The power of prana: Breathe your way to health and vitality: Sounds True (2011)

2. R. Rajagopal, S.N. Jois, M.S. Mallikarjuna, K.M. Anil, H. Shashidhar, Amelioration of mild and moderate depression through Pranic Healing as adjuvant therapy: randomised double-blind controlled trial, Australasian Psychiatry 26(1), 8287 (2018)

3. J.R. Starn, Energy Healing With Women Children, Journal of Obstetric, Gynecologic \& Neonatal Nursing 27(5), 576-579 (1998)

4. C.K. Sui, Pranic healing, S. Weiser (1990)

5. C.K. Sui, Advanced Pranic Healing: A Practical Manual on Color Pranic Healing: Energetic Solutions, Inc. (1992)

6. C.K. Sui, Miracles through pranic healing: Practical manual on energy healing: Energetic Solutions, Inc. (2004)

7. D.J. Tataryn, Paradigms of health and disease: a framework for classifying and understanding complementary and alternative medicine. The Journal of Alternative \& Complementary Medicine 8(6), 877-892 (2002)

8. G.A. Hurst, M.G. Williams, J.E. King, R. Viken, Faith-based intervention in depression, anxiety, and other mental disturbances, Southern Medical Journal 101(4), 388-392 (2008)

9. D.W. Wardell, J. Engebretson, Biological correlates of Reiki Touchsm healing, Journal of advanced nursing 33(4), 439-445 (2001)

10. K. Korotkov, D. DeVito, K. Arem, K. Madappa, B. Williams, L. Wisneski, Healing experiments assessed with electrophotonic camera. Subtle Energies \& Energy Medicine, Journal Archives 20(3) (2009)
11. K. Korotkov, O. Shelkov, A. Shevtsov, D. Mohov, S. Paoletti, D. Mirosnichenko, et al., Stress reduction with osteopathy assessed with GDV electrophotonic imaging: effects of osteopathy treatment, The Journal of Alternative and Complementary Medicin 18(3),251-257 (2012)

12. J. Polushin, A. Levshankov, D. Shirokov, K. Korotkov, Monitoring energy levels during treatment with GDV technique, J of Science of Healing Outcome 2(5), 5-15 (2009) 